\title{
A New Monitoring Device for the Force States of the Pressure Dispersed Anchor Cable
}

\author{
Qiang Shen ${ }^{1, a^{*}}$, De-ren Yuan ${ }^{2, b}$ and Cong-xin $\mathrm{CHEN}^{3, \mathrm{c}}$ \\ ${ }^{1}$ State Key Laboratory of Geomechanics and Geotechnical Engnieering, Institute of Rock and Soil \\ Mechanics, Chinese Academy of Sciences, Wuhan 430071,China \\ ${ }^{2}$ Guangxi Hebai highway Co., Ltd, Nanning 530022, China \\ ashenqzk@163.com, ${ }^{b}$ dr511749294@sina.com, ${ }^{c}$ cxchen@whrsm.ac.cn
}

\begin{abstract}
Keywords: Pressure dispersed anchor cable, Monitoring device; Force state.
Abstract. Because of the differences of the pull mechanism between the pressure dispersed anchor cable and the concentrated tension anchor cable, the stress states of each anchor cable cell of the pressure dispersed anchor is unable to be monitored by using the traditional anchor dynamometer. In this paper, a new monitoring device would be created for the force states of the pressure dispersed anchor cable, and the new device is consisted of three parts, the transferring force plate, the expending plate and the small anchor dynamometer. The new monitoring device can monitor the anchor cables stress state of the pressure dispersed anchor cables more conveniently and rapidly without altering the original anchor state. It provides direct references for designing the monitoring scheme of the pressure dispersed anchor cables' force state and monitoring the anchors construction. Finally, the new device has been used successfully to a practical engineering.
\end{abstract}

\section{Introduction}

As an active type reinforcement means, the prestress anchor cable can play the role of the potential self-supporting of the rock, and improve their strength and self-stability of geotechnical body, so its superiority is widely recognized and is used in a large number of the reinforcement project about landslides or slope in railways and highways ${ }^{[1]}$. Currently the concentrated tension anchor cable are the most widely used in the engineering, but in fact there are some problems were found by the engineer in the practical engineering. There exists the uneven distribution of bond stress on the anchoring segment of the concentrated tension anchor cable, so the stress concentration is found and the progressive failure is easier to happen on the anchoring segment. There are not only greatly reduce the anchorage strength, and difficult to ensure a permanent anchorage just because of the progressive failure. In order to solve these problems of the concentrated tension anchor cable, the pressure dispersed anchor cable began to be used in the practical engineering, which dispersed prestress applied to the each unit anchoring section located at different depths of the drill hole, so it overcome the deficiencies of stress concentration, and improve the bearing capacity of anchor ${ }^{[2-6]}$.

It is a very important part of the guiding for anchor design and construction that the anchor cable condition monitoring, and the monitoring results will provide an important basis for the anchor anchorage depth, the length of anchor, the loss of prestress and the anchor reinforcement effect. However there are differences in the mechanism between the concentrated tension anchor cable and the pressure dispersed anchor cable, so it can not measure the force status of each anchor unit of the pressure dispersed anchor cable by using the current traditional anchor dynamometer, and it can not effectively verify the validity of the pressure dispersed anchor cable for slope reinforcement. Therefore, it is very necessary to invent a new monitoring device for the force states of the pressure dispersed anchor cable.

A new monitoring device for the force states of the pressure dispersed anchor cable is invented in this paper for the mechanical characteristics of the pressure dispersed anchor cable. The new monitoring device is consisted of three parts, the transferring force plate, the expending plate and the small anchor dynamometer. On the basis of the original cable anchor, the transferring force plate and 
the expending plate would be added specifically to open the original anchor strand from the outside, so that the small anchor dynamometer could be installed on each strand anchor. By using the new monitoring device, the force states of each unit anchoring segment of the pressure dispersed anchor cable could be monitored in tensioning process or long-term monitoring, and the monitoring results are not only can effectively evaluate the effect of the dispersed pressure anchor reinforcement but also can be used to study the loss of prestress force of the pressure dispersed anchor cable, and more, its long-term monitoring results can also be used as a basis for evaluating the stability of the reinforcement object. Finally, the new device has been used successfully to a practical engineering.

\section{The design of the new monitoring device}

The traditional monitoring for the force states of the concentrated tension anchor cable generally use anchor dynamometer, which should be mounted between the anchor head and anchor plate, so the force states of anchor cable in the working state would be monitored. Because there are a plurality of unit anchoring body in the pressure dispersed anchor cable, and each unit anchoring body has a different anchoring segments and free section, therefore, it is unreasonable to monitor simply the force states of the pressure dispersed anchor cable by using the traditional anchor dynamometer, instead, the force states of each unit anchoring body should be monitored.

The new monitoring device for the force states of the pressure dispersed anchor cable includes three parts: anchor dynamometer, expanding plate and transferring force plate. The new monitoring device would be fixed in the original anchor plate by the anchorage ( Fig.1 ) .

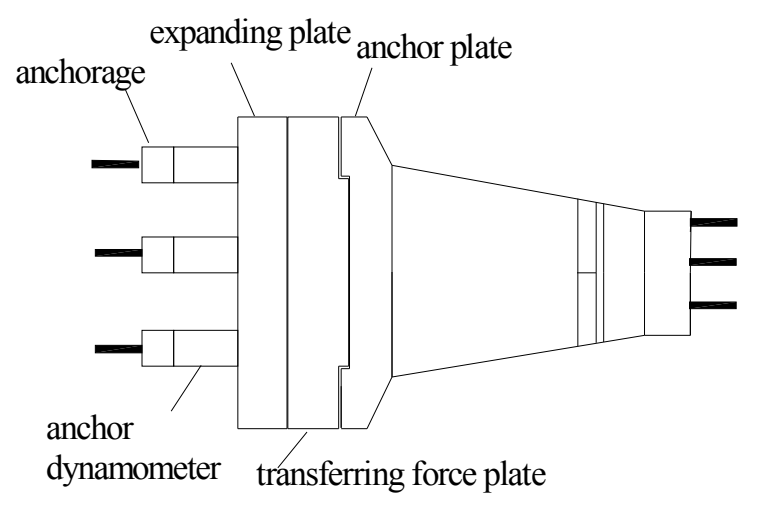

Fig.1 The structure scheme of the monitoring device (unit : $\mathrm{mm}$ )

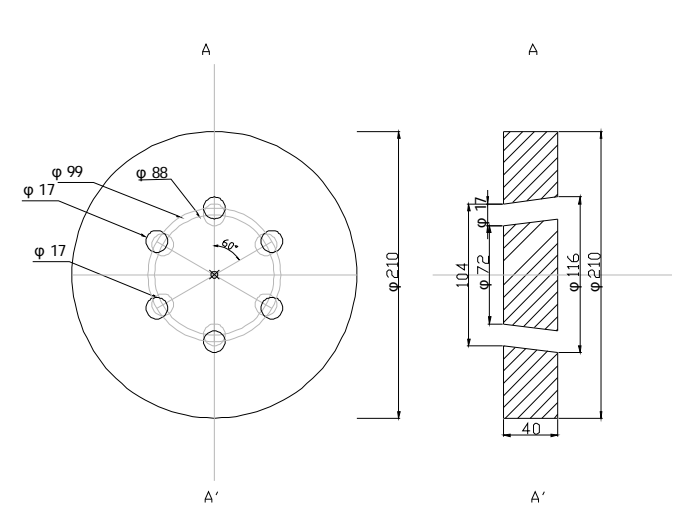

Fig.2 The sketch map of expanding plate

\section{anchor dynamometer}

Each unit of the anchor solid of the pressure dispersive anchor cable is generally composed of two steel strands, so the stress of the unit should be obtained when the force of the two strands is measured. An anchor dynamometer which uses a through-type sensor and can be directly output value strand stress should be used to measure the force of each steel strand. For a common pressure dispersive anchor cable which has three unit anchor solid and six steel strands, six anchor cable must be used to monitor the force state of the pressure dispersive anchor cable.

\section{expanding plate}

The expanding plate is a thick circular plate (Fig.2), whose role is to make the anchor strands of pressure dispersive anchor cable expanding the distance between each other in order to install anchor dynamometer and anchor plates. 


\section{transferring force plate}

The transferring force plate is a plate with a ring boss at one end(Fig.3), its main role is to focus on the thickness parts of the anchor plate, in order to avoid damage to the anchor plate by force.

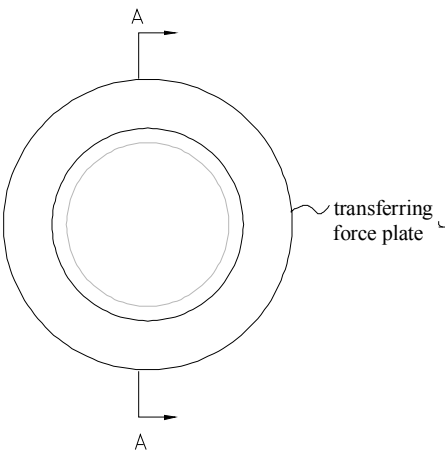

Fig.3 The sketch map of transferring force plate

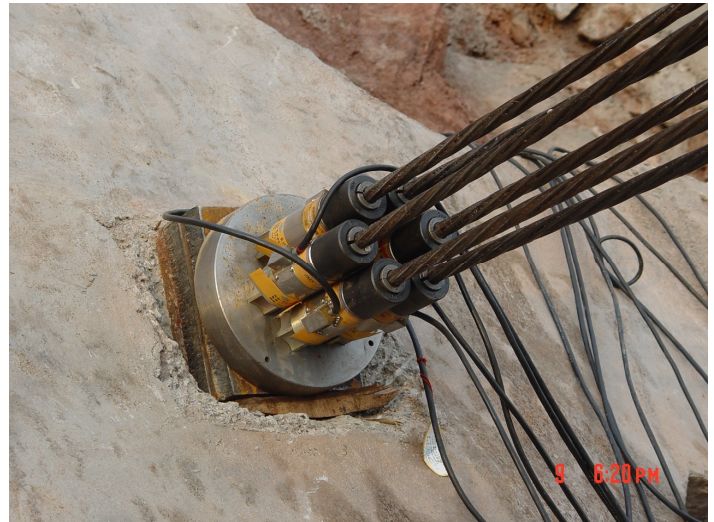

Fig.4 The picture of monitoring device in site

\section{Engineering applications}

\section{Project Overview}

There is up to $78 \mathrm{~m}$ high slope in a highway, and the pressure dispersed anchor cable are adopted as the primary means of strengthening for the slope in reinforcement design. The two anchor cable were selected as test anchor cables in site, the basic parameters of the testing anchor cables are listed in Table 1 .

Table 1 The basic parameters of testing anchor cables

\begin{tabular}{|c|c|c|c|c|}
\hline Load $/ \mathrm{kN}$ & $\begin{array}{c}\text { Steel } \\
\text { strand/root }\end{array}$ & $\begin{array}{c}\text { Borehole diameter } \\
/ \mathrm{mm}\end{array}$ & $\begin{array}{c}\text { Length of } \\
\text { anchorage section }\end{array}$ & Max Load $/ \mathrm{kN}$ \\
\hline 800 & 6 & 130 & 5 & 880 \\
\hline
\end{tabular}

\section{Monitoring the stress state of anchor cables}

\section{Installation of the new monitoring device in site}

Firstly, the anchor plate, transferring force plate, expanding device and anchor dynamometer were installed as shown in Figure 1, and the photos of the monitoring device in site after installation were shown in Figure 4.

\section{The tension test of anchor cables and test results}

The tension of the pressure dispersive anchor cable is carried out by using the gradual cyclic loading of each strand, firstly, the first steel strand of anchor cable should be tensioned to $10 \%$ of its design load and locked, and then the second steel strand, until all steel strand of anchor cable were tensioned to $10 \%$ of its design load and locked, then the next round of tension would be pulled, and the tensile load is $25 \%, 50 \%, 75 \%$, and $100 \%$ of the design load. The tensile test results are shown in Table 2.

From the results of tensile test, all the steel strands of anchor cable are pulled to the maximum load expected in the test, and all steel strands were no fracture and pulled out from the anchor solid of anchor cable, so the design and construction of the pressure dispersive anchor cable can meet the needs of the project. 
Table 2 The summary sheet of trial results

\begin{tabular}{|l|l|l|l|}
\hline Anchor number & anchor dynamometer number & $\begin{array}{l}\text { Length of Steel } \\
\text { atrond } / \mathrm{m}\end{array}$ & Load locked/kN \\
\hline \multirow{5}{*}{1 \# anchor } & 300242 & 20 & 131.7 \\
\cline { 2 - 4 } & 300231 & 25 & 136.8 \\
\cline { 2 - 4 } & 300261 & 30 & 133.6 \\
\cline { 2 - 4 } & 326032 & 20 & 131.8 \\
\cline { 2 - 4 } 2 \# anchor & 320032 & 25 & 137.7 \\
\cline { 2 - 4 } & 300272 & 30 & 134.2 \\
\hline \multirow{5}{*}{} & 326064 & 15 & 129.3 \\
\cline { 2 - 4 } & 323024 & 20 & 135.7 \\
\cline { 2 - 4 } & 327001 & 25 & 132.7 \\
\cline { 2 - 4 } & 300204 & 15 & 138.4 \\
\cline { 2 - 4 } & 363025 & 20 & 134.5 \\
\cline { 2 - 4 } & 300269 & 25 & \\
\hline
\end{tabular}

\section{Analysis of prestress loss of anchor cable}

After the tensile test, the two anchor cables are locked and monitored continuously for prestress loss, and the results are shown in Figure 5 and Table 3.
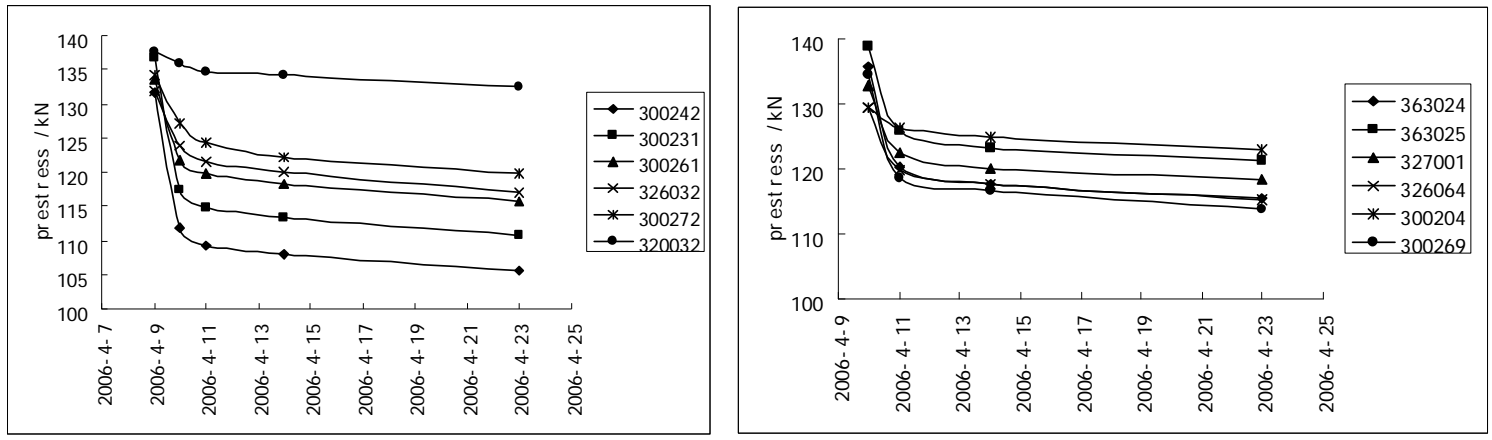

Fig.5 The curves of prestress of anchor cable changing with the time

Table. 3 The prestress loss quantity of the anchor cables

\begin{tabular}{|c|c|c|c|c|c|}
\hline $\begin{array}{l}\text { Anchor } \\
\text { number }\end{array}$ & $\begin{array}{l}\text { anchor } \\
\text { dynamometer } \\
\text { number }\end{array}$ & $\begin{array}{l}24 \mathrm{~h} \\
\text { prestress } \\
\text { loss } / \mathrm{kN}\end{array}$ & $\begin{array}{l}\text { 24hPrestress } \\
\text { loss rate/\% }\end{array}$ & $\begin{array}{l}\text { 15d prestress } \\
\text { loss } / \mathrm{kN}\end{array}$ & $\begin{array}{l}15 \mathrm{~d} \text { prestress } \\
\text { loss rate/\% }\end{array}$ \\
\hline \multirow{6}{*}{$\begin{array}{l}1 \# \\
\text { anchor }\end{array}$} & 300242 & 19.9 & 15.1 & 26.2 & 19.9 \\
\hline & 300231 & 19.4 & 14.2 & 26.1 & 19.1 \\
\hline & 300261 & 11.9 & 8.9 & 17.8 & 13.3 \\
\hline & 326032 & 8 & 6.1 & 14.8 & 11.2 \\
\hline & 320032 & 1.8 & 1.3 & 5.3 & 3.8 \\
\hline & 300272 & 7 & 5.2 & 14.4 & 10.7 \\
\hline \multirow{6}{*}{$\begin{array}{l}2 \# \\
\text { anchor }\end{array}$} & 326064 & 9.6 & 7.4 & 14 & 10.8 \\
\hline & 323024 & 15.4 & 11.3 & 20.2 & 14.9 \\
\hline & 327001 & 10.2 & 7.7 & 14.5 & 10.9 \\
\hline & 300204 & 3.1 & 2.4 & 6.4 & 4.9 \\
\hline & 363025 & 13 & 9.3 & 17.6 & 12.7 \\
\hline & 300269 & 15.9 & 11.8 & 20.7 & 15.4 \\
\hline
\end{tabular}


From these monitoring results of anchor cables, the prestress of $24 \mathrm{~h}$ has a large loss when the anchor cables are locked, the average loss rate of prestress of the two anchor cables is about $8.3 \%$ and $8.5 \%$ of the locking load. while the average loss rate of $15 \mathrm{~d}$ is about $11.6 \%$ and $13 \%$ of the locking load respectively, which indicates that the prestress loss occurs mainly in the $24 \mathrm{~h}$ after the anchor cables are locked. So we can divide prestress loss into three stages. The first stage is the stage with rapid loss of prestress, in this stage the prestress loss of the cable is increased sharply and the time of the stage is about $24 \mathrm{~h} \sim 48 \mathrm{~h}$ after the anchor cables are locked, and the loss of prestress is about $10 \%$ of the locked load, and the loss of Prestress is mainly due to the occurrence of slip of anchorage cable, relaxation of steel strand and the rock mass deformation and other factors. The second stage is the stage with slow loss of prestress, and the time of the stage is about $48 \mathrm{~h} \sim 96 \mathrm{~h}$ after the anchor cables are locked, and the prestress loss of the cable in the second stage only accounts for a small part of the whole prestress loss. The third stage is the stage of prestress stability, in this stage the prestress loss of the cable is almost over and the time of the stage is about $5 \mathrm{~d} \sim 15 \mathrm{~d}$ after the anchor cables are locked, and the anchor cables are working effectively.

\section{Conclusion}

In the paper, a new monitoring device is created for the stress state of the pressure dispersed anchor cable. The new monitoring device can monitor the anchor cables stress state of the pressure dispersed anchor cable more conveniently and rapidly without altering the original anchor state. It provides direct references for designing the monitoring scheme of the pressure dispersed anchor cables' force state and monitoring the anchors construction. And more, the new device has been used successfully to a practical engineering. The new monitoring device also has got the invention patent.

\section{Acknowledgement}

This research was financially supported by the National Natural Science Foundation of China(No. 11072256) and Guangxi transportation standardization project of China.

\section{Reference}

[1] LI Ning, ZHANG Ping, LI Guoyu. Discussion on design principle and method of prestressed cable for support of rock slopes[J]. Chinese Journal of Rock Mechanics and Engineering, 2004,23(17):2972-2976

[2]ODAKA H, ZHANG Manliang, SIMAYMA M. Study of load dispersion-type anchor and bond stress in peripheral soils[C] CHENG Liangkui, LIU Qichen ed. Application and Development of Anchorage Technology in Geotechnical Reinforcement Engineering. Beijing:Wanguo academic Press , $1996: 216-221$

[3] LI Haimin, LIU Chengzhou, LI Xin, et a1. Design research and application of large tonnage dispersed compressive stress anchoring cables [J]. Chinese Journal of Rock Mechanics and Engineering, 2002,21(Supp.1):2284-2289

[4] LIU Jianguo, WU Ping, YIN Huagang, et a1. Pressure-dispersive anti-float anchor technique and its application to engineering[J]. Chinese Journal of Rock Mechanics and Engineering,2005,24(21) : $3948-3953$

[5] XlA Changhua, Xueming. Application of compression decentralized prestressed cables in slope reinforcement [J]. Exploration Engineering(Drilling and Tunneling),2006,(4):35-37 
[6] Barley A D,Chris R.Windsor.Recent advances in ground anchor and ground reinforcement technology with reference to the deveiopment of the art proc[A].International Conference on Geotechnical and Geotechnical Engineering[C].Melbourne,2000 